\title{
Vitamin D status and its adequacy in healthy Danish perimenopausal women: relationships to dietary intake, sun exposure and serum parathyroid hormone
}

\author{
Christine Brot ${ }^{1}$, Peter Vestergaard ${ }^{2}$, Niels Kolthoff ${ }^{3}$, Jeppe Gram ${ }^{4}$, Anne P. Hermann ${ }^{2}$ and \\ Ole H. Sørensen ${ }^{1}$ \\ ${ }^{1}$ Osteoporosis Research Clinic, Dep 545, Copenhagen University Hospital Hvidovre, Kettegaard Allé 30, \\ DK- 2650 Hvidovre, Denmark \\ ${ }^{2}$ Department of Endocrinology and Metabolism, Aarhus Bone and Mineral Research Group, Aarhus Amtssygehus, \\ Tage Hansens Gade 2, DK-8000 Aarhus C, Denmark \\ ${ }^{3}$ Department of Clinical Physiology, Hilleroed Hospital, Helsevej 2, DK- 3400 Hilleroed, Denmark \\ ${ }^{4}$ Department of Endocrinology, Odense University Hospital, Sdr. Boulevard 29, DK-5000 Odense C, Denmark
}

\begin{abstract}
We conducted this study to assess the prevalence of vitamin D insufficiency in a population of normal perimenopausal women, to examine the influence of sun exposure and vitamin D intake on the concentration of 25-hydroxyvitamin D (25OHD) and to examine the association between parathyroid hormone (PTH) and 25OHD. A total of 2016 healthy women aged 45-58, who had recently undergone a natural menopause, were enrolled over a $2 \cdot 5$-year period in the Danish Osteoporosis Prevention Study. A marked seasonal fluctuation of 25OHD was seen, with an abrupt rise in June and high values until October. The fluctuation could be related to number of hours of sunshine per month with a two months time lag. Dietary vitamin D intake, vitamin supplementation, sunlight exposure, and use of sun-bed were all significantly related to $25 \mathrm{OHD}$ concentrations. Sun exposure seemed to contribute the most. The overall prevalence of vitamin $\mathrm{D}$ deficiency (defined as serum $25 \mathrm{OHD}=<25 \mathrm{nmol} / \mathrm{l}$ ) was $7 \%$. However, in the subgroup avoiding direct sunshine and abstaining from vitamin D supplementation $32.8 \%$ were vitamin $\mathrm{D}$ deficient in the winter-spring period. Although mean PTH was increased in the group with low serum 25OHD, PTH was not a sensitive marker of hypovitaminosis D in the individual, as only $16 \%$ of those with vitamin D deficiency had PTH levels above normal range. Thus, we have shown, that healthy middle-aged Danish women are prone to vitamin D insufficiency in the winter-spring period, if they avoid sun exposure in the summer period and abstain from vitamin D supplementation.
\end{abstract}

25-Hydroxyvitamin D: Parathyroid hormone: Vitamin D deficiency

\section{Introduction}

During the last decade many efforts have been aimed at redefining nutritional adequacy, in order to reduce the risk of chronic disease in addition to more traditional evidence of sufficiency, such as absence of classical deficiency diseases. Not least vitamin D has attracted attention in view of the worldwide epidemic of osteoporosis and the overwhelming evidence of the high prevalence of deficiency in elderly populations (McKenna, 1992).

Vitamin D is essential for normal calcium and bone metabolism. The circulating concentration of 25-hydroxyvitamin $\mathrm{D}$ (25OHD) is considered a good marker of vitamin
D status as it represents the cumulative effects of dietary intake of vitamin D and exposure to sunlight (Holick, 1996). However, defining the optimal level of 25OHD, which would ensure development and maintenance of a healthy skeleton has proven not to be an easy task. The threshold for vitamin D deficiency is generally considered to be at a serum 25OHD level below $25 \mathrm{nmol} / \mathrm{l}(10 \mathrm{ng} / \mathrm{ml})$ (Parfitt et al. 1982). However, there is increasing evidence that more subtle alterations in calcium and bone metabolism occur at 25OHD levels, which were earlier thought to be adequate. These unfavourable changes include impaired calcium absorption (Kinyamu et al. 1997; Zittermann et al. 1998), slight elevations in serum parathyroid hormone

\footnotetext{
Abbreviations: FSH, follicle-stimulating hormone; 25OHD, 25-hydroxyvitamin D; PTH, parathyroid hormone.

* Corresponding author: Dr Christine Brot, The Danish Veterinary and Food Administration, Mørkhøj Bygade 19, DK-2860 Søborg, Denmark, fax +4533956696, email cxb@fdir.dk
} 
(PTH) (Krall et al. 1989; Kinyamu et al. 1998) leading to increased bone turnover and accelerated bone loss (Dawson-Hughes et al. 1991; Chapuy et al. 1996). The cut-off level between this state of insufficiency and the replete state remains to be defined, but it has been stated to probably exceed $50 \mathrm{nmol} / \mathrm{l}(20 \mathrm{ng} / \mathrm{ml})$ by McKenna \& Freaney (1998). Among younger adults, the prevalence of vitamin D deficiency has been reported to be low in the USA (McKenna, 1992; Kinyamu et al. 1997), quite common in the southern part of Europe (Burnand et al. 1992; Chapuy et al. 1997), and moderate in Scandinavia (Lund \& Sørensen, 1979; Aksnes et al. 1988; Landin-Wilhelmsen et al. 1995). The prevalence of vitamin D insufficiency is obviously dependent on the limit chosen, but is likely to be very common.

How much vitamin $\mathrm{D}$ we must produce or ingest to achieve the optimal concentration of 25OHD is another key question. The main source of vitamin $\mathrm{D}$ is exposure to sunlight, but a number of factors, such as latitude, season, time of the day, use of topical sunscreens, influence the cutaneous production of vitamin D (Holick, 1996). At the latitude of Denmark $\left(54-58^{\circ} \mathrm{N}\right)$, no cutaneous vitamin D production occurs from October to April (Webb et al. 1988). During that period, maintenance of vitamin D level is dependent on oral vitamin D intake and on the stores of vitamin $\mathrm{D}$ built up during the previous summer. In Denmark, there is no food fortification with vitamin D. However, half the population takes vitamin supplementation either all year, or at least during wintertime (Lund \& Sørensen, 1979; Andersen et al. 1995). From the Danish national dietary survey it appears that the average vitamin D intake was $3.4 \mu \mathrm{g}$ daily, and only $10 \%$ of the adult population had vitamin $\mathrm{D}$ intakes at or above the RDA (5 $\mu \mathrm{g}$ per day) (Andersen et al. 1995).

There is little scientific information relating vitamin D intake and sun exposure to vitamin D status as determined by serum 25OHD and PTH concentrations in large adult population groups.

The present study was conducted to assess the prevalence of vitamin $\mathrm{D}$ insufficiency in a population of normal perimenopausal women, to estimate the relative influences of sun exposure and vitamin D intake on the concentration of 25OHD and to examine the relationship between PTH and 25OHD.

\section{Material and methods}

\section{Subjects}

The present study is part of an ongoing long-term multicentre trial on hormone replacement therapy, the Danish Osteoporosis Prevention Study (DOPS) (Mosekilde et al. 1999). A total of 2016 healthy perimenopausal Caucasian women were recruited from the general community by direct mailing. The inclusion criteria were (1) intact uterus, age 45-58 years and 3-24 months past last menstrual bleeding or perimenopausal symptoms (including menstrual irregularities) and elevated serum follicle stimulating hormone (FSH); (2) hysterectomized, age 45-52 years and elevated serum FSH. The following exclusion criteria were applied: (1) osteoporotic fractures of the spine verified by X-ray; (2) metabolic bone disease; (3) current oestrogen use, but former use of up to 3 months was accepted; (4) former treatment with corticosteroids for a period longer than 6 months; (5) presence of hyper- and hypothyroidism; (6) any chronic disease if newly diagnosed or out of control; (7) liver disease or unstable cardiac disease; (8) current or past malignant disease; (9) ever hospitalized due to ethanol abuse or drug addiction; (10) a history of deep thrombophlebitis and stroke. Women fulfilling these criteria were biochemically screened, ensuring that all had serum concentrations of ionized calcium, alanine aminotransferase, creatinine and thyroid stimulating hormone within normal reference limits. The inclusion period lasted 2.5 years, from November 1990 to March 1993. The present study is a cross-sectional study of baseline data.

\section{Biochemical measurements}

During the first visit, blood samples were obtained from the subjects under fasting conditions between 8 and 11 a.m. Serum was stored at $-80^{\circ} \mathrm{C}$ until analysis and had a single thaw at time of analysis. Serum levels of 25OHD were measured in one laboratory by a competitive assay using rachitic rat binding protein (Lund \& Sørensen, 1979). The lower detection limit was $12.5 \mathrm{nmol} / \mathrm{l}$. The intra- and interassay precisions were $8.3 \%$ and $10.2 \%$, respectively. Vitamin $\mathrm{D}_{2}$ and $\mathrm{D}_{3}$ metabolites were measured together by the method.

Serum intact PTH was measured with Immulite intact PTH immunoassay kit in 1097 women (i.e. those participating in the centres of Aarhus and Copenhagen). The lower limit of detection was $0.3 \mathrm{pmol} / \mathrm{l}$. The intra- and interassay precisions were $5.4-7.0 \%$ and $5.0-5.5 \%$, respectively. The normal range had been established in 196 healthy blood donors (both genders, age 20-60 years) and was $1.3-7.6 \mathrm{pmol} / \mathrm{l}$.

Serum bone specific alkaline phosphatase was analysed by lectin precipitation, intra-assay variation $8 \%$, interassay $25 \%$ (Brixen et al. 1989).

\section{Vitamin D intake}

Dietary vitamin D intakes were estimated by using diet records in 1907 subjects (94.6\% of the cohort). The study started up with 4-day diet records, which were later extended to 7-day records to improve the precision of the assessments of nutrients intake. In the whole population, $626(32.8 \%)$ performed diet records for four consecutive days, $1272(66.7 \%)$ performed 7-day records, and nine participants $(0.5 \%)$ performed either $2,3,5$ or 6-day records. The 4-day records included one weekend day (either from Wednesday to Saturday or from Sunday to Wednesday). Participants recorded all foods and beverages that were consumed daily in an open-ended form, estimating quantities in household measures. They received oral and written instructions and the importance of keeping accurate records was explained. A trained dietitian reviewed the records with the majority of the participants so as to obtain additional information to improve the estimation of food intake. A small number of participants 


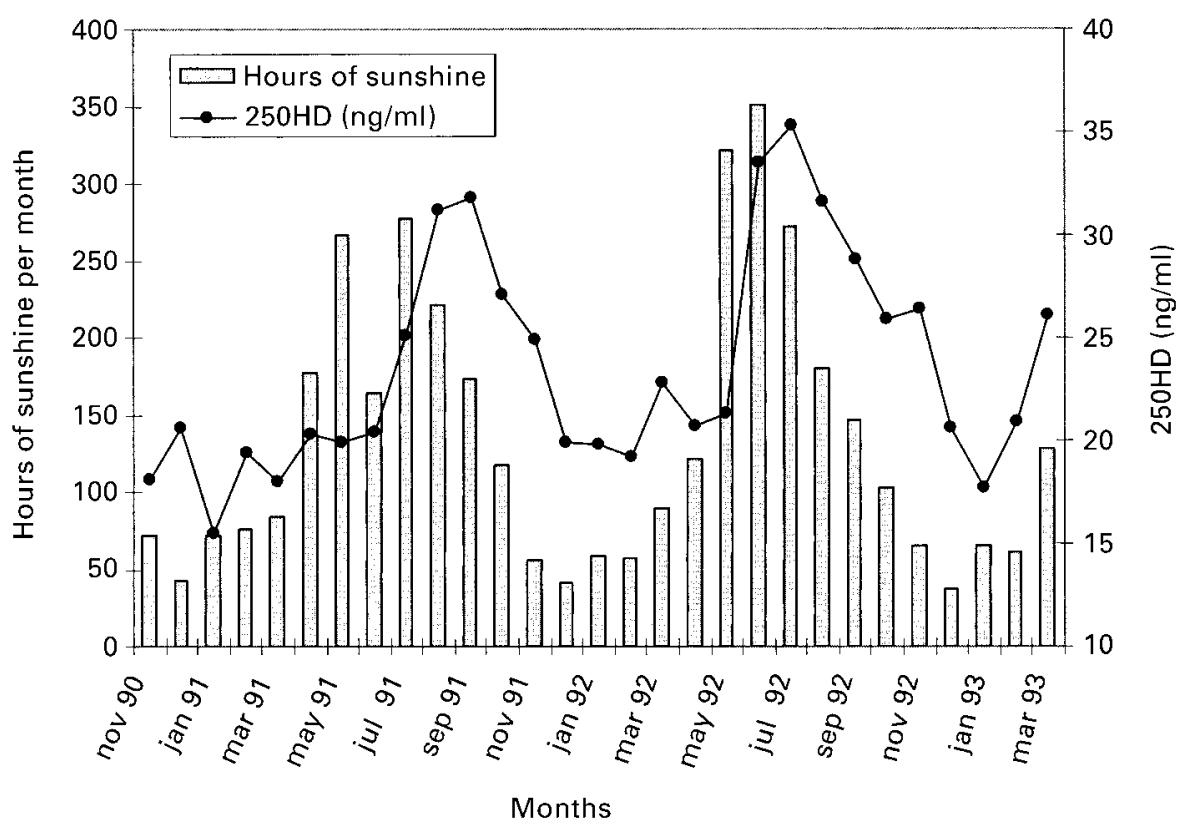

Fig. 1. Relationship between hours of sunshine and serum 25OHD. $\mathbf{\square}$, Hours of sunshine; $\bullet, 25 \mathrm{OHD}(\mathrm{ng} / \mathrm{ml})$.

did not encounter the dietitian, but filled in and mailed the forms. These participants were contacted by telephone if necessary to clarify unclear matters. All food records were analysed for nutrients intake by using Dankost Software version 1.3b, a program based on the official Danish food table (Møller, 1989). There was a small difference in the estimates of vitamin D intake between the 4-day and the 7day records: mean vitamin D intake was $2.9 \mu \mathrm{g}$ and $3.1 \mu \mathrm{g}$, respectively $(P<0.01)$. Because of the large sample size, the difference of $0 \cdot 2 \mu \mathrm{g}$ is significant, but it is not clinically relevant, for which reason data were pooled.

The subjects were asked to state whether or not they took vitamin D supplementation for at least half of the year (in Denmark, the majority of dietary supplements that include vitamin D contain $200 \mathrm{IU}$, which equals $5 \mu \mathrm{g}$ cholecalciferol).

\section{$U V$-exposure}

In each of the four centres, all the subjects were interviewed by the same two doctors. The degree of sunlight exposure was assessed by asking the subjects a simple question which enabled them to be categorized into three groups: 'How frequently do you expose yourself to sunlight lightly dressed, either with the purpose of getting sun-tanned or during the course of various outdoor activities like sport or gardening?' The interviewer selected which one of the following categories most accurately described their behaviour: 'Never' meant that the person preferred not to stay in direct sunlight, but, as we are dealing with normally active middle-aged persons, casual sun exposure occurred in daily life; 'Occasionally' meant that the person sometimes spent time outdoors in the sunshine; 'Regularly' meant that the person quite often intendedly exposed themselves to sunshine. The question focused on sun exposure because direct solar radiation is the major source of UVB, even though a minor part of the UVB radiation is scattered around.

The use of artificial 'sun-beds' was registered (no $=0$, yes $=1$ ).

Data on the number of hours of bright sunshine in each of the inclusion months were obtained from the Danish Institute of Meteorology.

\section{Statistical analysis}

Serum 25OHD was logarithmically transformed in order to achieve a normal distribution. The relationship between logarithmated serum 25OHD as dependent variable and daily intake of vitamin $\mathrm{D}$ in foods, vitamin supplementation (coded as: 0, no supplements; 1, use of supplements at least for some of the year), use of solarium (yes/no), and whole body exposure to sunlight (coded as a dichotomous variable: 0, 'never'; 1, 'occasionally' or 'regularly') as independent variables were examined using multiple regression analysis with all independent variables entered into the model. Linear and non-linear regression analysis was performed between PTH and serum 25OHD. All $P$-values are two-tailed. Significance limit was $P=<0 \cdot 05$. The analyses were performed with the Fastat Statistics Package for Macintosh.

The study was approved by the Ethics Committee of Copenhagen, and written informed consent was obtained from all subjects.

\section{Results}

\section{Determinants of serum $250 H D$}

Sixty-three percent of the population took vitamin supplementation at least during wintertime. This group had a 


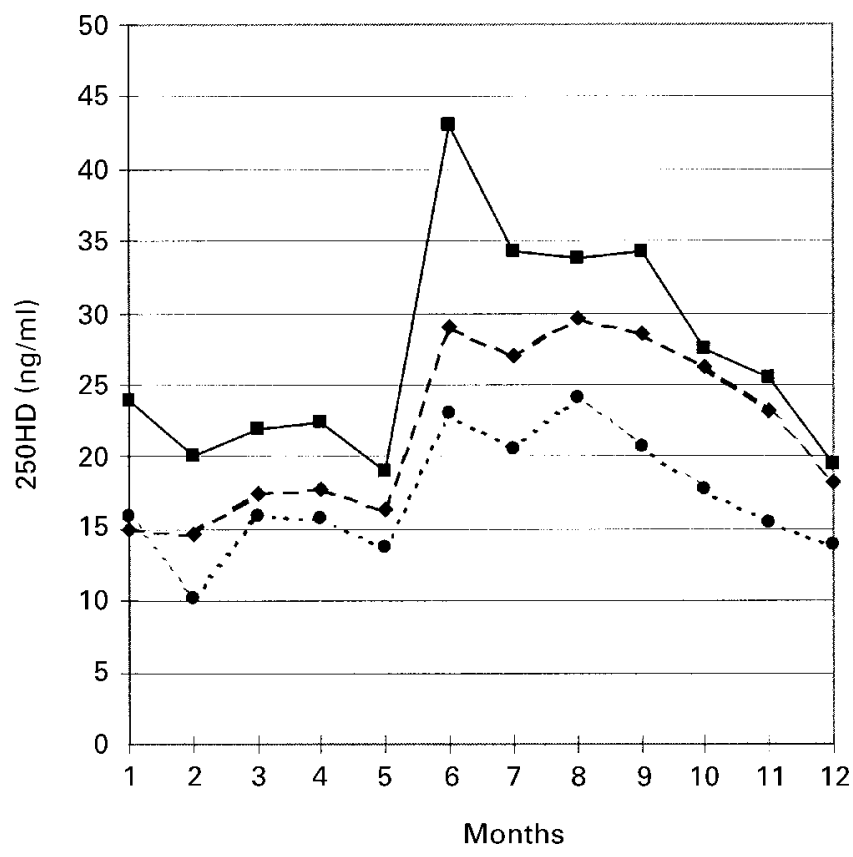

Fig. 2. Seasonal fluctuation of serum $250 H D$ according to frequency of sun exposure. $\mathbf{\square}$, Regular sun exposure; $\bullet$, occasional sun exposure; $\bullet$, avoiding direct sun exposure.

higher mean serum 250HD than the rest: 66.0 versus $57.5 \mathrm{nmol} / \mathrm{l}$. The mean difference $(95 \% \mathrm{CI})$ was $8.5 \mathrm{nmol} / \mathrm{l}$ $(6 \cdot 3-10 \cdot 8)$.

There was a seasonal fluctuation of serum 25OHD, with an abrupt rise in concentration in June and highest values from June to October. This fluctuation could be related to number of hours of sunshine, with a 2 months time lag (Fig. 1). The impact of sun exposure on 25OHD is shown in Fig. 2, which illustrates the changes in those (37\%) who did not take vitamin supplementation. Low mean serum 25OHD levels were seen during the whole year among those reporting never to sunbathe. A modest seasonal variation was seen in this group, as an expression of the casual sun exposure, which invariably occurs in free-living persons. Higher 25OHD levels than the rest of the population were observed all year round among those reporting regular exposure to sunshine with marked seasonal variation.

The relative contributions of UV exposure and oral vitamin $\mathrm{D}$ intake in determining serum $250 \mathrm{HD}$ were further quantified in multiple regression analysis, the results of which are shown in Table 1. Increasing intake of vitamin D in foods, active sunbathing, use of solarium, and use of vitamin supplements all significantly increased mean annual serum vitamin D. Active sunbathing seemed to contribute the most to high vitamin D status $(27.6 \%$ more with active sunbathing) whereas vitamin $\mathrm{D}$ in foods contributed relatively little $(9.0 \%$ more per $5 \mu \mathrm{g}$ vitamin $\mathrm{D}$ per day). During the summer-autumn period dietary intake lost its significance.

\section{Prevalence of hypovitaminosis $D$}

Overall, $7 \%$ of the population had 25OHD levels = $<25 \mathrm{nmol} / 1$ (3 \% during summer and autumn and $11 \%$ in winter and spring). Only one subject had 25OHD below detection limit. The prevalence of vitamin D insufficiency, defined as 25OHD concentrations below $50 \mathrm{nmol} / \mathrm{l}$ was $39.7 \%$ (58.9 \% during summer and autumn and $23.0 \%$ in winter and spring). However, $32.8 \%$ of those avoiding direct sunshine and not taking vitamin pills had serum $25 \mathrm{OHD}$ levels $=<25 \mathrm{nmol} / 1$ during winter and spring, and $79.7 \%$ had serum 25OHD levels below $50 \mathrm{nmol} / \mathrm{l}$ (Table 2).

\section{PTH and bone specific alkaline phosphatase}

An inverse relationship exists between PTH and 25OHD (Pearsons correlation $r=-0.14, P<0.001$ ). Thus, mean PTH increased with decreasing $25 \mathrm{OHD}$ concentrations. In the subgroup with $25 \mathrm{OHD}$ concentrations $=<25 \mathrm{nmol} / 1$,

Table 1. Factors associated with serum 25-hydroxyvitamin D

\begin{tabular}{|c|c|c|c|}
\hline Variable† & Regression coefficient $\beta$ (SE) & $\begin{array}{l}\text { Increases in } \\
250 H D \ddagger(\%)\end{array}$ & $T$ \\
\hline \multicolumn{4}{|l|}{ The whole population } \\
\hline Dietary vitamin D intake ( $\mu \mathrm{g} /$ day) & $0.018(0.004)^{\star \star}$ & 1.8 per $\mu g$ & 4.47 \\
\hline Use of vitamin supplements (1: yes, $0:$ no) & $0.146(0.023)^{\star \star}$ & $15 \cdot 7$ higher for 'yes' & $6 \cdot 39$ \\
\hline Whole body exposition to sunlight (1: yes, 0 : no) & $0.244(0.032)^{\star \star}$ & $27 \cdot 6$ higher for 'yes' & $7 \cdot 61$ \\
\hline Use of sun-bed (1: yes, $0:$ no) & $0.124(0.026)^{\star \star}$ & 13.2 higher for 'yes' & 4.87 \\
\hline \multicolumn{4}{|l|}{ Subpopulation included from December to May } \\
\hline Dietary vitamin D intake ( $\mu \mathrm{g} /$ day) & $0.025(0.006)^{\star \star}$ & 2.5 per $\mu \mathrm{g}$ & $4 \cdot 32$ \\
\hline Use of vitamin supplements (1: yes, $0:$ no) & $0.183(0.031)^{\star \star}$ & 20.1 higher for 'yes' & 5.84 \\
\hline Whole body exposition to sunlight (1: yes, 0 : no) & $0.207(0.045)^{\star \star}$ & 23.0 higher for 'yes' & 4.55 \\
\hline Use of sun-bed (1: yes, $0:$ no) & $0.177(0.035)^{\star *}$ & 19.4 higher for 'yes' & 4.99 \\
\hline \multicolumn{4}{|l|}{ Subpopulation included from June to November } \\
\hline Dietary vitamin D intake ( $\mu \mathrm{g} /$ day) & $0.008(0.005)$ & 0.8 per $\mu \mathrm{g}$ & 1.72 \\
\hline Use of vitamin supplements (1: yes, $0:$ no) & $0.076(0.028)^{*}$ & 7.9 higher for 'yes' & $2 \cdot 71$ \\
\hline Whole body exposition to sunlight (1: yes, $0:$ no) & $0.293(0.038)^{\star \star}$ & 34.0 higher for 'yes' & 7.63 \\
\hline Use of sun-bed (1: yes, $0:$ no) & $0.090(0.005)^{\star}$ & 9.4 higher for 'yes' & 2.90 \\
\hline
\end{tabular}

${ }^{\star} P<0.01 ;{ }^{\star \star} P<0.001$.

$\dagger$ Analysed in multiple regression model containing these variables and with logarithm of serum 25-hydroxyvitamin $D$ as dependent variable.

¥ The regression coefficients $\beta$ has been antilogarithmated to fit actual serum vitamin $D$ value. The figures express percentage change in serum $250 H D$. 
Table 2. Prevalence of low vitamin D status during winter and spring according to sun exposure and vitamin supplementation

\begin{tabular}{|c|c|c|c|c|c|c|}
\hline \multirow[b]{2}{*}{ Behavioural pattern: } & \multicolumn{2}{|c|}{ Avoiding direct sunshine ${ }^{*}$} & \multicolumn{2}{|c|}{ Occasional sun exposure ${ }^{\star}$} & \multicolumn{2}{|c|}{ Regular sun exposure* } \\
\hline & $\begin{array}{l}\text { No vitamin } \\
\text { supplement }\end{array}$ & $\begin{array}{l}\text { +vitamin } \\
\text { supplement }\end{array}$ & $\begin{array}{l}\text { No vitamin } \\
\text { supplement }\end{array}$ & $\begin{array}{l}\text { +vitamin D } \\
\text { supplement }\end{array}$ & $\begin{array}{l}\text { No vitamin } \\
\text { supplement }\end{array}$ & $\begin{array}{l}\text { +vitamin } \\
\text { supplement }\end{array}$ \\
\hline Mean serum 25OHD (nmol/l) & $36 \cdot 5$ & $45 \cdot 3$ & 41.5 & $49 \cdot 3$ & $53 \cdot 5$ & $62 \cdot 3$ \\
\hline Percentage of the cohort & $6 \cdot 6 \%$ & $7.6 \%$ & $16 \cdot 6 \%$ & $28.4 \%$ & $13.9 \%$ & $26.9 \%$ \\
\hline \multicolumn{7}{|l|}{ Percentage of the subgroups with: } \\
\hline Serum $25 \mathrm{OHD}=<25 \mathrm{nmol} / \mathrm{I}$ & $32.8 \%$ & $12 \cdot 9 \%$ & $17.6 \%$ & $10 \cdot 7 \%$ & $9.8 \%$ & $2 \cdot 8 \%$ \\
\hline Serum $25 \mathrm{OHD}<50 \mathrm{nmol} / \mathrm{I}$ & $79.7 \%$ & $72.9 \%$ & $75 \cdot 2 \%$ & $57.9 \%$ & $53.5 \%$ & $39.1 \%$ \\
\hline Mean serum intact PTH (pmol/l) & $5 \cdot 2$ & $4 \cdot 4$ & $4 \cdot 3$ & 3.9 & 3.9 & $3 \cdot 8$ \\
\hline
\end{tabular}

To convert values for 25 -hydroxyvitamin $\mathrm{D}(25 \mathrm{OHD})$ to $\mathrm{ng} / \mathrm{ml}$, multiply by 0.4 .

* The dietary intake of vitamin $\mathrm{D}$ did not differ between the groups and was on average $3.1 \mu \mathrm{g}$ per day.

mean PTH was $5 \cdot 2 \mathrm{pmol} / \mathrm{l}$, corresponding to an increase of $1.2 \mathrm{pmol} / \mathrm{l}$ (95\% CI: 0.6-1.9) when compared to the rest of the study group.

In an attempt to further characterize the relationship between PTH and 25OHD, we performed linear and nonlinear regression analyses:

$$
\begin{aligned}
& \text { Linear: PTH }=4.6341-0.0235 \times 25 \mathrm{OHD} \\
& \text { Logarithmic: PTH }=6.1206-0.6681 \times \ln (25 \mathrm{OHD}) \\
& \text { Cubic: PTH }=5.4406-0.0994 \times 25 \mathrm{OHD}+0.0018 \times \\
& \quad(25 \mathrm{OHD})^{2}-1 \times 10^{-5} \times(25 \mathrm{OHD})^{3} \\
& \text { Power: PTH }=5.3665 \times(25 \mathrm{OHD})^{-0.1319} \\
& \text { Exponential: PTH }=3.9968 \times \mathrm{e}^{-0.0046}
\end{aligned}
$$

Even though some of the models fitted well, the predictive value of the models was not very high, as they explained only $1.2-2.7 \%$ of the total variation.

The variability of PTH increased with decreasing $25 \mathrm{OHD}$ concentrations. Thus, only $16.2 \%$ of those with $25 \mathrm{OHD}=<25 \mathrm{nmol} / 1$ had elevated PTH values (Table 3 ). Overall, $4.7 \%$ had PTH value above normal range, the majority of them having 25OHD values of $25-75 \mathrm{nmol} / \mathrm{l}$. In fact, only when 25OHD levels exceeded $100 \mathrm{nmol} / \mathrm{l}$, were all PTH measurements within the normal range.

No relationship could be demonstrated between 250HD and bone specific alkaline phosphatase.

\section{Discussion}

Our data confirm the well-established predominant influence of sun exposure on vitamin status (Holick, 1996). At the latitude of Denmark $\left(54-58^{\circ} \mathrm{N}\right)$, no cutaneous vitamin D synthesis occurs during 6-7 months of the year, making great demands on the vitamin D stores. The 2 months timelag between the increase in number of hours of sunshine and the rise in serum 25OHD concentration might be explained by the fact that in Denmark temperatures are still often too low for light clothing or sunbathing in April and May. Holick (1996) has estimated that for elderly people, the exposure of hands, face, and arms to suberythemal doses of radiation (10-15 min between 11 am and $2 \mathrm{pm}$ ) two to three times a week in the summer would satisfy a requirement of $400 \mathrm{IU} /$ day of vitamin D. It appears from our results, with the limitations of a crosssectional study, that it requires regular sun exposure during the summer to build up sufficient stores to ensure adequate vitamin $\mathrm{D}$ status during winter and spring, even in younger persons. Use of artificial sun-beds seemed to have the same predictive effect on serum $25 \mathrm{OHD}$ as vitamin supplementation, although it is usually held that sun-beds contribute marginally to endogenous production of vitamin $\mathrm{D}$, as they transmit only small amounts of ultraviolet $\mathrm{B}$ radiation. However, this estimate may be biased as the women using sun-beds regularly are also those who sunbathe most frequently. We do not have information regarding use of sunscreens, which are known to impair cutaneous vitamin D production, but data were gathered in the early 1990s before the campaigns recommending use of sunscreens. That the influence of supplementary vitamin D in this study seemed to have higher impact per microgram on serum $25 \mathrm{OHD}$ than dietary vitamin $\mathrm{D}$, might be due to the use of short-term diet records, resulting in imprecise estimates of dietary vitamin $\mathrm{D}$ intake.

The overall prevalence of vitamin $\mathrm{D}$ deficiency of $7 \%$ (3\% during summer and $11 \%$ during winter) is in accordance with earlier Scandinavian reports (Lund \& Sørensen, 1979; Aksnes et al. 1988; Landin-Wilhelmsen et al. 1995). However, the subgroup avoiding direct sun exposure attracts attention; during late wintertime and spring $32 \%$ had serum 25OHD concentration below $25 \mathrm{nmol} / \mathrm{l}(10 \mathrm{ng} / \mathrm{ml})$ and $90 \%$ below $62.5 \mathrm{nmol} / 1$ $(25 \mathrm{ng} / \mathrm{ml})$. These middle-aged women are, in our study healthy, living a normal life, and are therefore exposed to

Table 3. Prevalence of PTH measurements above normal range according to serum 25hydroxyvitamin D levels

\begin{tabular}{lccc}
\hline Serum 25OHD & $=<25 \mathrm{nmol} / \mathrm{l}$ & $25-50 \mathrm{nmol} / \mathrm{l}$ & $>50 \mathrm{nmol} / \mathrm{l}$ \\
\hline Percentage of the population & $6.7 \%$ & $33.2 \%$ & $60.1 \%$ \\
Mean serum intact PTH (pmol/l) & 5.2 & 4.2 & 3.8 \\
Percentage with elevated PTH levels & $14.9 \%$ & $5.4 \%$ & $2.8 \%$ \\
\hline
\end{tabular}

To convert values for 25 -hydroxyvitamin $\mathrm{D}(25 \mathrm{OHD})$ to $\mathrm{ng} / \mathrm{ml}$, multiply by 0.4 . 
some UV radiation on face and hands during daily life activities. Therefore, a seasonal variation is also found in this group, although of modest amplitude. Even though it is only a minority of the total cohort, it is worrying that their vitamin D status is so low. Their way of life is probably similar to the majority of the best-functioning elderly. For many older people, the development of vitamin D deficiency has often been attributed to the lack of sunlight, rather than to the effects of ageing (Egsmose et al. 1987). In accordance with this, the SENECA study found 25OHD levels among 70-76-year-old persons comparable to the values in our subgroup that avoided sun exposure (van der Wielen et al. 1995).

Several authors have attempted to delimit the boundary between vitamin $D$ insufficiency and sufficiency. In a number of cross-sectional studies, performed among both young and elderly age groups and with wide geographic dispersion, the threshold serum 25OHD concentration below which mean PTH level increased ranged from $37.5 \mathrm{nmol} / \mathrm{l}(15 \mathrm{ng} / \mathrm{ml})$ to $110 \mathrm{nmol} / \mathrm{l}(44 \mathrm{ng} / \mathrm{ml})$ (Krall et al. 1989; Chapuy et al. 1997; Dawson-Hughes et al. 1997; Thomas et al. 1998). Malabanan et al. (1998) have shown that $50 \mathrm{nmol} / 1(20 \mathrm{ng} / \mathrm{ml})$ was the minimal $25 \mathrm{OHD}$ concentration at which PTH no longer decreased when vitamin D supplementation was administered. When using the value of $50 \mathrm{nmol} / \mathrm{l}$ as threshold, the majority of our subjects could be considered to be in a state of insufficiency at least in the winter period. Whether or not, values below this level for 6 months a year, socalled transient insufficiency, are harmful when repeated for many years remains unclear. As long as there is a lack of long-term longitudinal studies of the consequences of various levels of serum $25 \mathrm{OHD}$, we will have to rely on recommendations for adequate vitamin D levels based on presumptions from well-known conditions of deficiency. This study, which is planned to be continued over 20 years, will hopefully bring us closer to an answer.

PTH and 25OHD were inversely related and the group with serum 25OHD concentrations below $25 \mathrm{nmol} / \mathrm{l}$ had $31 \%$ increased mean PTH, which corresponds to approximately $0.5 \mathrm{SD}$. The inverse relationship between 25OHD and PTH is of particular interest, because PTH is a potent bone-resorbing agent and even slight elevations in serum PTH (i.e. in the same order of magnitude as our findings) is associated with increased bone turnover and accelerated bone loss, which may be prevented by vitamin D supplementation (Dawson-Hughes et al. 1991; Chapuy et al. 1996).

However, it is undoubtedly important to consider not only the mean value but the proportion of subjects in whom the PTH level is above normal range. In the daily clinical situation, PTH measurements are often used to identify the degree of hypovitaminosis D. Hyperparathyroidism is commonly seen among population groups who have had persistently very low serum 25OHD levels for some time, like frail elderly people or immigrants (Egsmose et al. 1987; Henriksen et al. 1995). In our material, where seasonal fluctuation was seen among all groups, most of the women with low serum $25 \mathrm{OHD}$ values were only deficient for part of the year. This might explain why only a relatively small proportion of them had secondary hyperparathyroidism (15\% of those with serum 25OHD below $25 \mathrm{nmol} / \mathrm{l}$ ). Furthermore, the majority of the women with serum PTH levels above the normal range had serum $25 \mathrm{OHD}$ concentrations of $25-100 \mathrm{nmol} / \mathrm{l}$. In free-living elderly people in the USA, and in a large sample of normal middle-aged French men and women, normal PTH levels have also been registered in the majority of subjects with low serum 25OHD levels (Chapuy et al. 1997; Kinyamu et al. 1998; Gallagher et al. 1998). Therefore, PTH does not seem to be a sensitive marker of vitamin D deficiency in the single person. Nor is bone-specific alkaline phosphatase, as we found no relationship between serum 25OHD and this parameter.

In conclusion, we have shown in this cross-sectional study, that healthy middle-aged Danish women are prone to vitamin D insufficiency in the winter-spring period, if they avoid sun exposure in the summer period and abstain from vitamin D supplementation. With few very simple questions about sunbathing habits and vitamin supplementation, which are practicable in every doctor's surgery, we were able to identify a group of whom one-third were vitamin D deficient and $90 \%$ could be considered as in a state of insufficiency during the winter-spring season. Being able to select patients at risk by easy means is of great importance both for the practitioner and for health authorities.

It also appears from our results that although PTH and 25OHD were inversely related, PTH measurement cannot be used to diagnose hypovitaminosis $\mathrm{D}$ in the individual.

\section{Acknowledgements}

The authors thank Dr Lars Bjørn Jensen, Dr Bo Abrahamsen, and Dr Pia Eiken for collecting data for the study. They also thank Dr Lars Ovesen, the Danish Veterinary and Food Administration, for reading and discussing the manuscript. They also gratefully acknowledge the statistical assistance of Lene Theil Skovgaard, associate professor at the department of biostatistics of the University of Copenhagen.

The study was financed by the Karen Elise Jensens Foundation.

\section{References}

Aksnes L, Rødland O \& Aarskog D (1988) Serum levels of vitamin $\mathrm{D}_{3}$ and 25-hydroxyvitamin $\mathrm{D}_{3}$ in elderly and young adults. Bone and Mineral 3, 351-357.

Andersen NL, Fagt S, Groth MV, Hartkopp HB, Møller A, Ovesen L \& Warming DL (1995) The Danish National Dietary Survey 1995. Main results. The National Food Agency, publication 235, 114-115.

Brixen K, Nielsen HK, Eriksen EF, Charles P \& Mosekilde L (1989) Efficacy of wheat germ lectin-precipitated alkaline phosphatase in serum as an estimator of bone mineralization rate: comparison to serum alkaline phosphatase and serum bone Gla-protein. Calcified Tissue International 44, 93-98.

Burnand B, Sloutskis D, Gianoli F, Cornuz J, Rickenbach M, Paccaud F \& Burckhardt P (1992) Serum 25-hydroxyvitamin D: distribution and determinants in the Swiss population. American Journal of Clinical Nutrition 56, 537-542. 
Chapuy MC, Preziosi P, Maamer M, Arnaud S, Galan P, Hercberg S \& Meunier PJ (1997) Prevalence of vitamin D insufficiency in an adult normal population. Osteoporosis International 7, 439-443.

Chapuy MC, Schott AM, Garnero P, Hans D, Delmas PD \& Meunier PJ, EPIDOS study group (1996) Healthy elderly French women living at home have secondary hyperparathyroidism and high bone turnover in winter. Journal of Clinical Endocrinology and Metabolism 81, 1129-1133.

Dawson-Hughes B, Dallal GE, Krall EA, Harris S, Sokoll LJ \& Falconer G (1991) Effect of vitamin D supplementation on wintertime and overall bone loss in healthy postmenopausal women. Annals of Internal Medicine 115, 505-512.

Dawson-Hughes B, Harris S \& Dallal GE (1997) Plasma calcidiol, season, and serum parathyroid hormone concentrations in healthy elderly men and women. American Journal of Clinical Nutrition 65, 67-71.

Egsmose C, Lund B, McNair P, Lund B, Storm T \& Sorensen OH (1987) Low serum levels of 25-hydroxyvitamin D and 1,25dihydroxyvitamin $\mathrm{D}$ in institutionalised old people: influence of solar exposure and vitamin D supplementation. Age and Ageing 16, 35-40.

Gallagher JC, Kinyamu HK, Fowler SE, Dawson-Hughes B, Dalsky GP \& Sherman SS (1998) Calciotropic hormones and bone markers in the elderly. Journal of Bone and Mineral Research 13, 475-482.

Henriksen C, Brunvand L, Stoltenberg C, Trygg K, Haug E \& Pedersen JI (1995) Diet and vitamin D status among pregnant Pakistani women in Oslo. European Journal of Clinical Nutrition 49, 211-218.

Holick MF (1996) Vitamin D and bone health. Journal of Nutrition 126, 1159S-1164S.

Kinyamu HK, Gallagher JC, Balhorn KE, Petranick KM \& Rafferty KA (1997) Serum vitamin D metabolites and calcium absorption in normal young and elderly free-living women and in women living in nursing homes. American Journal of Clinical Nutrition 65, 790-797.

Kinyamu HK, Gallagher JC, Rafferty KA \& Balhorn KE (1998) Dietary calcium and vitamin D intake in elderly women: effect on serum parathyroid hormone and vitamin D metabolites. American Journal of Clinical Nutrition 67, 342-348.

Krall E, Sahyoun N, Tannenbaum S, Dallal G \& DawsonHughes B (1989) Effect of vitamin D intake on seasonal variations in parathyroid hormone secretion in postmenopausal women. New England Journal of Medicine 321, 1777-1783.
Landin-Wilhelmsen K, Wilhelmsen L, Wilske J, Lappas G, Rosén T, Lindstedt G, Lundberg P-A \& Bengtsson B-A (1995) Sunlight increases serum $25(\mathrm{OH})$ vitamin $\mathrm{D}$ concentration whereas $1,25(\mathrm{OH})_{2} \mathrm{D}_{3}$ is unaffected. Results from a general population study in Göteborg, Sweden (the WHO MONICA project). European Journal of Clinical Nutrition 49, 400-407.

Lund B \& Sørensen OH (1979) Measurement of 25-hydroxyvitamin $\mathrm{D}$ in serum and its relation to sunshine, age and vitamin D intake in the Danish population. Scandinavian Journal of Clinical and Laboratory Investigation 39, 23-30.

McKenna MJ (1992) Differences in vitamin D status between countries in young adults and the elderly. American Journal of Medicine 93, 69-77.

McKenna MJ \& Freaney R (1998) Secondary hyperparathyroidism in the elderly: means to defining hypovitaminosis D. Osteoporosis International suppl. 8, S3-S6.

Malabanan A, Veronikis IE \& Holick MF (1998) Redefining vitamin D insufficiency. Lancet 351, 805-806.

Møller A (1989) Food Composition Tables 1989. Publication no. SC3. Copenhagen: National Food Agency.

Mosekilde L, Hermann AP, Beck-Nielsen H, Charles P, Pors Nielsen S \& Sørensen OH, Danish Osteoporosis Prevention Study Research Group (1999) The Danish Osteoporosis Prevention Study (DOPS): project design and inclusion of 2000 normal perimenopausal women. Maturitas 31, 207-219.

Parfitt AM, Gallagher JC, Heaney RP, Johnston CC, Neer R \& Whedon GD (1982) Vitamin D and bone health in the elderly. American Journal of Clinical Nutrition 36, 1014-1031.

Thomas MK, Lloyd-Jones DM, Thadhani RI, Shaw AC, Dereska DJ, Kitch BT, Vamvakas EC, Dick IM, Prince RL \& Finkelstein JS (1998) Hypovitaminosis D in medical inpatients. New England Journal of Medicine 338, 777-783.

van der Wielen R, Löwik M, van der Berg H, de Groot L, Haller J, Moreiras O \& van Staveren W (1995) Serum vitamin D concentrations among elderly people in Europe. Lancet 346, 207-210.

Webb AR, Kline LW \& Holick MF (1988) Influence of season and latitude on the cutaneous synthesis of vitamin $\mathrm{D}_{3}$ : exposure to winter sunlight in Boston and Edmonton will not promote vitamin $\mathrm{D}_{3}$ synthesis in human skin. Journal of Clinical Endocrinology and Metabolism 67, 337-338.

Zittermann A, Scheld K \& Stehle P (1998) Seasonal variations in vitamin D status and calcium absorption do not influence bone turnover in young women. European Journal of Clinical Nutrition 52, 501-506. 